\title{
GILLES DELEUZE, FILÓSOFO DO FUTURO ${ }^{1}$
}

\section{Gregory Flaxman}

\section{RESUMO}

As cicatrizes, queimaduras, erupções do filósofo são apenas as figurações mais literais das emoções que se depositam em nossas faces - as emoções que a filosofia em si precisa conceitualizar, por sua vez. Para Deleuze, a própria natureza do conceito emerge de tais "contatos imediatos" com algo sem precedentes e até mesmo apocalíptico, que não pode ser representado, mas, no entanto, precisa ser pensado. O filósofo sci phi usa a sensação de seus encontros em seu corpo e sua mente, quer estas sejam marcas que entalharam sua carne delicada, ou as impressões fora-deste-mundo que se resolveram em expressões, ou as experiências que formaram as dobras delicadas da matéria cinza.

\section{PALAVRAS-CHAVE}

Filosofia; Ficção científica; Imagem

\section{GILLES DELEUZE, PHILOSOPHER OF THE FUTURE}

\section{ABSTRACT}

The scars, burns, and rashes of the philosopher are only the most literal figurations of the affects that deposit themselves on our faces-the affects which philosophy itself must conceptualize in turn. For Deleuze, the very nature of the concept emerges from such "close encounters" with something unprecedented and even apocalyptic, which cannot be represented but must be thought nonetheless. The sci philosopher wears the sensation of his encounters on his body and brain, whether these are marks that have sculpted his or her delicate flesh, or the out-of-this-world impressions that have resolved themselves in expressions, or the experiences that have formed the delicate folds of gray matter.

\section{KEYWORDS}

Philosophy; Science fiction; Image

\footnotetext{
1 Tradução do original em inglês por Mara Verônica Suassuna Lopes. Revisão Técnica: Antonio Carlos Amorim.
} 
$\underline{\mathrm{Um}}$

Sempre que lhe era perguntado a respeito do futuro da filosofia, e isso acontecia com freqüência, Deleuze respondia com impaciência. "É bastante penoso", ele admitiu, uma vez que tal especulação invariavelmente sujeita o futuro ao lúgubre estado de ânimo (Stimmung) do presente. Perguntamos sobre o futuro da filosofia, como se fosse uma alma inquieta, cujas perspectivas tenham se tornado objeto de um crescente e terrível prognóstico: O que restará disso? Sobreviverá? Ou como Deleuze ironiza, “estará morto”? (1987, p. 1) Este sentimento não poderia ser removido para além da própria inclinação filosófica de Deleuze. De fato, Deleuze construiu sua jubilosa criação de conceitos em virtude de recusar o senso comum do que todos sabem, ou por extensão, o bom senso do que todos predizem. Afinal de contas, ele se pergunta: o que é o futuro senão aquele que passa por toda espécie de especulação, evitando as probabilidades e previsões do presente, e "dando início aos devires que ocorrem silenciosamente, e quase sempre de forma imperceptível?” (1987, p. 2)

Com isto em mente, podemos começar agora pela inversão da questão quanto ao futuro da filosofia e desta forma perguntar como podemos falar a respeito de uma filosofia do futuro. Esta questão poderia ser tida como a composição de toda obra de Deleuze, assim dedicada ao plano da imanência desterritorializada dos tradicionais constituintes da filosofia tradicional (por exemplo: sujeito e objeto), porém ele rapidamente dá os créditos a Nietzsche como o primeiro a propor esta questão como um problema e um projeto. O subtítulo da obra de Nietzsche, Além do Bem e do Mal, "Prelúdio de uma Filosofia do Futuro", efetivamente indica a reorientação da filosofia para longe do senso comum e do bom senso e voltado para o desconhecido e o incompreensível. Deleuze escreve: "Segundo Nietzsche, descobrimos, que mais profundo que o tempo e a eternidade, é a atemporalidade”, que consiste em "agir contra o tempo passado e, assim, atuar sobre o nosso tempo e, espera-se, em benefício de um tempo que está por vir” (1994, p. xxi).

Talvez seja à luz deste desafio que devamos entender a insistência de Deleuze de que a filosofia deve aspirar novos significados de expressão. "Está chegando o tempo, no qual quase não será possível escrever como se tem feito há tanto tempo”, Deleuze explica no prefácio Diferença e Repetição. Porém, se esta afirmação é freqüentemente citada, raramente é compreendida, devido à recomendação que a precede. Apenas uma página antes, no meio da descrição sobre a natureza da moderna filosofia, Deleuze diz: "Um livro de filosofia deve ser 
em parte uma espécie muito particular de história de detetive e também um tipo de ficçãocientífica” (1994, p. xx). O primeiro destes gêneros é facilmente receptivo aos procedimentos mais tradicionais de filosofia e isto também explica porque está tão presente nos primeiros trabalhos de Deleuze, devotado aos sinais e séries que permanecem sob a oscilação de um tipo de estruturalismo sutil. No entanto, no caso da ficção-científica, o qual nos interessa aqui, é mais desconcertante e problemático. À primeira vista—vamos admitir—somos tentados a tomar a sugestão de Deleuze como uma brincadeira, quase uma "pilhéria", como se a analogia entre filosofia e ficção-científica marcasse a distância entre a esfera privilegiada das Idéias nobres e a imaginação genérica dos enredos populares.

Longe de invocar a declamação dos códigos de Klingon, ou o proferir das parábolas de Jedi, a exortação de Deleuze, contudo, deve ser entendida no sentido no qual os alemães interpretam a ficção científica como “Zunkunftsroman” ou o "livro do futuro”. O que significaria, literalmente, criar uma Zunkunftsphilosophie, uma filosofia do futuro? Sob os auspícios de um gênero devotado ao futuro, Deleuze parece dizer que a filosofia pode, no entanto, ocupar-se do problema do futuro, ao invés de predeterminar o seu próprio. Uma filosofia assim começa, como fez Nietzsche, situando-a em um tipo de terra incógnita-um lugar onde se apagaram os pontos de referência conhecidos. Tanto quanto parece que os vastos espaços e paisagens futurísticas de ficção científica estão totalmente em desacordo com as imagens-padrão de filosofia, este é precisamente o ponto de vista de Deleuze: a ficção científica sempre começa a partir do que conhecemos, colocando seus protagonistas em viagens, quer sejam físicas ou metafísicas, em direção a lugares ermos. Desde seus primeiros escritos, Deleuze nunca cessou de lamentar que o protótipo da abordagem filosófica omite-se em relação à questão do: “O que é...?” A estrutura dessa questão sempre nos tenta a conjeturar a respeito de uma essencial e abrangente resposta, mas a ficção-científica introduz um novo tipo de questão com a qual a filosofia pode também iniciar de outra maneira: “E se...?”. Considerando que a filosofia tradicionalmente retorna aqueles elementos transcendentes que existem além das vicissitudes do espaço e tempo, até mesmo do futuro, a questão do: “e se...?” presume a introdução de premissas totalmente diferentes, além da pretensão de um mundo real para a realidade das pretensões: a verdade, por assim dizer, de todas as questõesinclusive “o que é...?”-reside na inverdade ou fabulação que constituem um tipo de mise-enpensée para toda a filosofia. 
As eventualidades da ficção científica não são “deste mundo”, porque nelas, a integridade do nosso mundo desintegra-se, obliterada pela insistência de outras realidades ou deveríamos dizer pluralidade? "Acreditamos em um mundo no qual as individuações são impessoais e as singularidades, pré-individuais”, diz ele: este é “o esplendor da ficção científica” (DELEUZE, 1994, p. xxi). Anomalias metafísicas, desnorteantes mutações, rompem o tecido do espaço-tempo, abrem fendas no universo: a ficção científica introduz signos e imagens que "não podem ser calculados” de acordo com a ciência deste ou qualquer outro mundo, no entanto, por tudo isso, não podem ser desconsiderados. Ao invés de sustentar a natureza sacrossanta da ciência como conhecimento (Wissenschaft), a ficção científica compromete-se a tornar a ciência uma ficção, desviando seus fluxos de informações para todo tipo de realidades alternativas, ao mesmo tempo utópicas e cautelosas, estranhas e familiares. Como Deleuze escreve: "Dessa forma, estamos plenamente cientes de que, infelizmente, falamos a respeito da ciência de uma maneira não muito cientifica” (1994, p. xxi). Porém, não há nada realmente “desafortunado” acerca da ficcionalização da ciência, ou ao invés disso, não terá sido uma felicidade para a filosofia ter recuperado o sentido de fortuna, de um acontecimento casual ou de um devir? Para Deleuze, a ficção científica doa-se à filosofia no exato momento em que as próprias "fraquezas da última tornam-se manifestas”, o que vale dizer, quando a filosofia apropria-se da tarefa de determinar o futuro de acordo com o que julga possível. O problema com o possível—ao menos é dessa forma que se tende a entendêlo-é que ele limita o futuro a um espaço probabilística e estatisticamente governável, quando, na verdade, o futuro é definido por tantos caminhos bifurcados, tantas divergências, que não podemos considerar ou conciliar a todos eles, exceto como incompatíveis, ou mesmo “im-possíveis”. Não podemos conceber o futuro de acordo com um conjunto de possibilidades precisamente porque nenhum conjunto poderia completa ou consistentemente organizar o possível.

\section{$\underline{\text { Dois }}$}

Nesse aspecto, talvez possamos definir este problema particular da filosofia e, portanto, de sua ficcionalização da ciência no contexto da estética, o que tradicionalmente determina o campo de possibilidades para excluir a realidade do real. "É estranho que a estética (como ciência do sensível) possa ser fundada no que pode ser representado no sensível” o que Deleuze (1994) certa vez observou, pela insistência em considerar a estética de acordo com as condições de experiências possíveis, ou o que podemos simplesmente 
chamar de conceitos de representação, paradoxalmente define a experiência em antecipação da experiência. Em a Crítica da Razão Pura, por exemplo, Kant procura elaborar uma “estética transcendental” pela definição de conceitos que tornam as sensações possíveis e inteligíveis. Enquanto Kant afirma que a mente tem de estar "afetada de uma determinada maneira” para estimular o pensamento, e conseqüentemente muito trabalho de crítica, ele finalmente afasta-se da essência da sensibilidade que experimentamos a fim de oferecer uma exposição das condições de possibilidade para tal experiência ${ }^{2}$. Conseqüentemente, as condições de uma possível experiência são definidas previamente, como princípios que possuem o estado de correto, estas condições precisam ser aplicadas à experiência e, reciprocamente, a experiência tem que ser submetida a estas condições. Deleuze escreve: “A representação significa a síntese daquilo que é apresentado. A síntese, portanto, consiste no seguinte: uma diversidade é representada, isto é, é colocada como se fizesse parte de uma representação” (1990, p. 15).

Representar é “re-apresentar como...”, confiar os signos e acontecimentos da experiência a uma estrutura lingüístico-transcendental que existe anteriormente à experiência, antecipando o futuro em seus próprios hábitos. Subjugado a este regime, o sujeito da representação projeta esta estrutura de um momento para o próximo como uma "primeira repetição”, isto é, a continuidade de sua própria experiência. A modulação dos objetos no tempo, ou movimento é, desta forma, determinado em concordância com o hábito do próprio sujeito, um ambiente móvel, o qual se antecipa na prolepse do seu próprio senso comum. Esta síntese compreende tanto a reprodução quanto o reconhecimento, à medida que reproduzimos diferentes partes de espaço, através do tempo e, em seguida, vamos para além desta síntese, em virtude da relação das múltiplas representações com um objeto. Quer seja por inocência ou estupidez, a representação é fundamentada na promessa de todo e qualquer encontro é sujeito ao reconhecimento, que o que encontramos em um objeto, imagem, ou signo confirma nosso próprio esquema de representações. Por essa razão, a representação imagina que nós podemos considerar quase toda imagem, signo, ou fenômeno sob o sol, ou além dele, porque a representação existe em antecipação a toda imagem, signo ou fenômeno. Deleuze esclarece a respeito de Kant: “A antecipação é definida como sendo independente da experiência,

\footnotetext{
${ }^{2}$ Em seu primeiro livro A Filosofia Crítica de Kant (1963), Deleuze marca a distinção entre a completa noção da representação, alertando que sempre deve haver discriminação entre o que nos é apresentado como a diversidade sensível do fenômeno e as condições daquelas representações como "as puras formas de nossa intuição e nossa sensibilidade.” Gilles Deleuze, A Filosofia Crítica de Kant: tradução de Hugh Tomlinson e Barbara Habberjam (Minneapolis: University of Minnesota Press, 1990), p. 8.
} 
exatamente porque a experiência nunca nos ‘dá’ nada que seja universal e necessário” (1990, p. 11), mas o que devemos começar a compreender aqui é que, em virtude da sua extensão ao universal, a representação não é menos extensiva ao universo. Por isso, a permanente convicção de Kant de que as aptidões e limites da razão são tão completamente válidos como igualmente aplicáveis não somente para todos os seres humanos, mas também para qualquer inteligência alienígena. Kant parece ter se convencido, assim como muitos de seus contemporâneos, que Deus não poderia deixar de povoar todos os cantos do cosmos com todos os tipos de criaturas, mesmo que somente algumas provavelmente fossem inteligentes e mais avançadas, porém todas estariam sujeitas à faculdade da razão e da estrutura de representação.

O verdadeiro truque da representação é não apenas nos imaginar como o centro do universo, mas, no mesmo momento, projetarmos nossa própria imagem de volta para as estrelas. Entretanto, na visão Coperniana pessoal de Kant, nós humanos sofremos do princípio da arrogância suprema no qual não importa quão frio e solitário possa ser o nosso pequeno meio, conseguimos ver "os olhos do universo focados telescopicamente de todas as direções em suas ações e pensamentos” (NIETZSCHE, 1989. p. 246). Como Nietzsche (1989) refletiu: “Toda a regularidade que tanto nos impressiona acerca do curso das estrelas e dos processos químicos coincide fundamentalmente com as propriedades que nós mesmos projetamos às coisas, para que nos impressionemos com elas” (1989, p. 253). Da mesma forma que se pode explicar a regularidade com a qual, na ficção científica, aparentemente todas as espécies de alienígenas consigam falar inglês, isso também começa a sugerir as ilusões pelas quais nossa filosofia ficcional científica finalmente terá que passar. Por quê? Porque a representação combina com um espírito de iluminação que é endêmico à ficção científica. Em primeiro lugar, o gênero agrada, pois mostra os rudimentos da análise científica e da investigação lógica, por constituírem os mais básicos indicadores de seu cenário racional e tecnocrata. E, em segundo lugar, o progresso desta iluminação do espaço exterior (conforme sua duplicata terrestre) muito freqüentemente parte em busca de novos mundos, com a certeza de que, em qualquer lugar do universo, as leis e valores humanos prevalecerão e que as coisas são fundamentalmente as mesmas em toda parte. Se a ficção científica atinge a tantos como um gênero conservador, isto é porque seus vôos de utopia ou distopia muito freqüentemente confirmam valores tradicionais e idéias transcendentais, assegurando-nos sobre a coerência essencial do universo e do propósito da razão, do ideal de democracia e da permanente resiliência da família. A presunção melodramática com a qual, digamos, Steven Spielberg tem 
tratado a ficção cientifica é simplesmente a mais óbvia e exagerada instância da submissão prolongada do gênero à representação. No futuro da ficção científica, onde os perigos apocalípticos da ciência tecnológica potencialmente ameaçarem tudo que conhecemos e em que acreditamos, inclusive a própria humanidade, o regime de representação retornará como um monarca exilado para restaurar a ordem.

É contra esta tendência que Deleuze convoca a ficção científica. Devido à sua predileção pela representação, Deleuze afirma o reverso desta lógica: em outras palavras, talvez devêssemos dizer que a representação, neste caso, testemunha algo profundo, rebelde e revolucionário, para o qual a filosofia deve voltar-se. O aspecto corretivo da ficção científica, seu desejo de salvar o presente e remendar as próprias rupturas do espaço-tempo que o gênero apresenta, deve ser compreendido como o último retrógrado-e reativo-suspiro contra a emergência do incompreensível. À medida que a ficção científica encena aquelas situações nas quais os valores conservadores muitas vezes intervêm para, finalmente, resgatar o gênero de alternativas mais horrendas, de uma panóplia de outros feitos, assim, talvez possamos entender a afeição de Deleuze pelo gênero, o que deduzimos pela sua disposição em expandir essas alternativas, e em compeli-las a extremos delirantes e irreversíveis. Se na ficção cientifica em geral retrata os esforços deliberados do senso comum, podemos dizer que ela reúne todo o seu vasto mecanismo epistemológico exatamente a fim de criar encontros excepcionais e excepcionalmente enigmáticos que ultrapassam qualquer senso comum- 0 descobrimento de um estranho monólito em uma das luas de Júpiter (2001: Uma Odisséia no Espaço), a descoberta de uma, até então, desconhecida espécie biológica vinda de uma galáxia distante ( $O$ Enigma de Andrômeda), o aparecimento da esposa morta de um astronauta numa estação orbital espacial (Solaris).

$\underline{\text { Três }}$

Deleuze sempre recua da representação porque ela ameaça relegar a experiência do sensível ao domínio do possível e, portanto, do previsível. É por isso que ele se volta para a ficção científica, pois o gênero garante não apenas o compromisso genérico com um tipo de realismo (i.e., plausabilidade), mas também do compromisso sensato com a realidade de uma experiência, ainda que inexplicável, que a experiência possa provocar, mesmo que esta experiência chegue a ultrapassar os limites do senso comum. Sob este ponto de vista, alguns podem se surpreender que, em seu prefácio de Diferença e Repetição, onde ele invoca a 
ficção científica a fim de descrever o projeto de uma filosofia do futuro, Deleuze lamenta o fracasso de seu próprio livro. A despeito de sua declaração sobre a necessidade de escrever um livro de filosofia à semelhança da ficção científica, Deleuze parece considerar Diferença e Repetição aquém das expectativas. Em antecipação ao seu próximo livro, mas também com relação livro que havia escrito, escreve: “O que este livro deveria, portanto, ter tornado claro era o advento de uma coerência que não mais é nossa, da humanidade, mas de Deus ou do mundo. Neste sentido, deveria ter sido um livro apocalíptico”. (1994, p. xxi; itálicos meus). Em que sentido Deleuze deixa de realizar um apocalipse filosófico e que isto tem a ver com a criação de seu próprio sci phi?

Acima de tudo, Deleuze parece sugerir que a ficcionalização da filosofia encontra seu ponto de partida paradoxal na obrigatoriedade de deixar o mundo para trás—ou de destruí-lo. Na verdade, “sci phi” goza de uma relação particular com o apocalipse, que ele libera sobre o regime da representação a fim de desterritorializar o pensamento de suas amarras transcendentais: “o pensamento moderno nasce a partir do fracasso da representação, da perda de identidades, e da descoberta de todas as forças que atuam sob a representação do idêntico” (1994, p. xiv). Mas é aí também que o pensamento moderno fracassou. Apesar do caráter do filósofo contemporâneo, Deleuze sugere que devemos lutar contra o fato de que o “fracasso da representação” não evita sua perpetuação ou sua fantasia eterna. Continuamos convocando os constituintes de uma velha coerência a despeito do “advento” de uma nova. É como se os acontecimentos da modernidade tivessem passado despercebidos, como se a anúncio de desastre ainda não tivesse chegado. Ainda estamos esperando- como cidadãos do interior, como as pessoas na parábola de Kafka—até que a palavra nos alcance? Ou será que escolhemos ignorar as notícias, rir delas, como o bom povo na parábola de Nietzsche, que trata a proclamação de que "Deus está morto” com desdém? Ou, ainda, será que já nos atingiram, nós ouvimos e internalizamos a mensagem, e inconscientemente "escolhemos" reprimi-la? Talvez este seja o significado do próprio inconsciente—o de recusar-se a entender, de entender mal, de permanecer despreparado, sem vontade e incapazes.

Em qualquer dos casos, o livro apocalíptico reúne a aniquilação das três grandes formas de transcendência com a qual a coerência da filosofia está tipicamente associada, isto é, o que Deleuze chama de Deus, Humanidade e o Mundo (uma coerência que não mais é nossa, da humanidade, mas de Deus ou do mundo. Neste sentido, deveria ter sido um livro apocalíptico). A missão do sci phi consiste em realizar precisamente esta tripla morte- 
primeiro, a morte de Deus, do juízo divino cuja "razão suficiente" carregava o fardo de escolher o melhor mundo possível; segundo, a morte do homem, a quem o juízo (a "Lei” abstrata) caía na ausência de Deus ou do Bem transcendente; e, terceiro, a morte da tradicional ontologia ou Ser. Como já havíamos sugerido, a primeira ou divina execução aplica-se a Nietzsche, embora ele rapidamente reconhecesse a limitação da morte de Deus. Em uma das seções mais memoráveis de The Gay Science, Nietzsche descreve como um louco entra correndo no Mercado para anunciar a morte de Deus-e é recebido com risos. Depois, ele reflete: "Este enorme evento ainda está a caminho, ainda vagando-ainda não atingiu os ouvidos dos homens. Raios e trovões levam tempo; a luz das estrelas leva tempo; os atos, embora realizados, ainda levam tempo para serem vistos e ouvidos” (1974, p.125). Um grande número de cidadãos, diz Nietzsche, são descrentes, ateus, mas estas pessoas não abandonaram o divino, apenas o colocaram em outro lugar. Daí, a destruição da segunda forma de transcendência. Como afirma Deleuze, esta tarefa cabe a Foucault, que dissolveu o sujeito em uma disposição de forças historicamente específicas. "Nós já podemos ver que as forças dentro do homem não contribuem necessariamente para a composição de uma FormaHumana, mas, ao contrário, pode ser investida em outro composto ou forma,” escreve Deleuze em Foucault, acrescentando que "mesmo que durante um curto período de tempo, o Homem nem sempre existiu, e não existirá para sempre” (1999, p. 124). No entanto, a destruição do transcendente permanece abortiva, realizada dentro de uma estrutura para logo depois ser disposta em outra, o mundo da substância.

A fim de compreender este jogo de conchas metafísico, podemos considerar que, em cada caso de transcendência, estamos, entretanto, lidando com a presença de um tipo de teologia. Isto é suficientemente óbvio sob os auspícios de Deus, para quem a criação, a decisão, a causa e, portanto, a representação são aludidas em última instância. Na ausência de Deus, no entanto, a função da transcendência passa ao sujeito e à governância de suas faculdades, as quais submetem um fenômeno de sensibilidade à determinação (síntese). A plenitude da transcendência divina abre caminho para a Forma-Humana, que legisla de acordo com uma trancendência vazia (não Deus, mas o Bem). Finalmente, com a morte do Homema Forma-Humana, sujeito do significador — a transcendência assume a forma da substância, do Ser, que reside no coração de tantas ontologias modernas. A substância é o último assegurador da transcendência, e certamente o mais próximo à imanência, porém ele ainda retarda a imanência. Mesmo na admirável filosofia da imanência, de Spinoza, onde o plano da natureza é composto das várias modalidades da substância, Deleuze afirma que aquela 
transcendência ainda não foi deslocada: as modalidades referem-se a Deus, "a natureza naturando-se.” Em relação a isso, a exortação para que a filosofia se torne um tipo de ficção científica deveria ser tomada como a obrigação literal de liberá-la deste último fundamento substancial, do pretenso Ser, mas como Deleuze rapidamente reconhece, ele não conseguiu levar a cabo esta destruição: “deveria ter sido um livro apocalíptico...” Como podemos destruir a transcendência substancial—“o mundo”-sem destruir a coerência de uma nova (ou, na verdade, qualquer) filosofia? Este apocalipse não nos libertaria de qualquer solo firme, espalhando “nossas” moléculas no mero caos?

\section{$\underline{\text { Quatro }}$}

Embora o sentido de uma filosofia não-fundacional e de uma nova metafísica permeie quase tudo que Deleuze escreve após Diferença e Repetição, principalmente com Félix Guattari, a eventualidade do apocalipse e, portanto, do sci phi, surge verdadeiramente no final de sua vida. Em $O$ que é a Filosofia?, Deleuze e Guattari encenam a produção da filosofia e sua criação de conceitos em uma espécie de pós-apocalipse. Assim como muitos trabalhos de ficção científica, os quais se iniciam após o fim do mundo (de holocausto nuclear, catástrofe biológica, invasão alienígena, extermínio da civilização, etc.), o “construtivismo” da filosofia deve se desenvolver e orientar seus procedimentos em relação a uma prévia destruição cuja fonte precisa talvez nunca cheguemos a conhecer. No entanto, - e esta é a idéia de Deleuze-a filosofia não começa com a destruição, mas, ao invés disso, com aqueles que presenciaram o apocalipse, com os videntes e sobreviventes cujas faces carregam as marcas de um evento inconcebível. O platonismo nos diz que a alma do filósofo tocou o céu, enquanto a ficção científica nos lembra que este vôo visionário-esta anamnesetambém empresta ao filósofo um ar de loucura. O vidente de estranhos sinais, de olhos arregalados, o cientista louco trabalhando para inventar novas máquinas, o intrépido explorador buscando desesperadamente pela vida em outras terras: o novo filósofo, por sua vez, se tornará cada uma deles, e cada um será ridicularizado por ter se tornado um estranho em seu mundo.

O filósofo sci phi usa a sensação de seus encontros em seu corpo e sua mente, quer estas sejam marcas que entalharam sua carne delicada, ou as impressões fora-deste-mundo que se resolveram em expressões, ou as experiências que formaram as dobras delicadas da matéria cinza. Pense no protagonista de Contatos Imediatos, cuja busca literal e existencial 
começa quando ele, viajando em seu caminhão, avista um OVNI tarde da noite: quando coloca o rosto para fora da janela, a luz ofuscante da nave que paira acima do caminhão deixa uma marca de queimadura no lado exposto de seu rosto. As cicatrizes, queimaduras, erupções do filósofo são apenas as figurações mais literais das emoções que se depositam em nossas faces - as emoções que a filosofia em si precisa conceitualizar, por sua vez. Para Deleuze, a própria natureza do conceito emerge de tais “contatos imediatos” com algo sem precedentes e até mesmo apocalíptico, que não pode ser representado, mas, no entanto, precisa ser pensado. Considere, por um instante, o conceito (ou o conceito do conceito) que Deleuze e Guattari criam nas páginas iniciais de $O$ que é a Filosofia?:

Existe, em um dado momento, um mundo calmo e tranqüilo. De repente, um rosto amedrontado surge e olha para alguma coisa fora do campo. A outra pessoa não aparece aqui como sujeito nem como objeto, mas como algo que é diferente: um mundo possível, a possibilidade de um mundo assustador. Este possível mundo não é real, nem ainda não, mas, no entanto, existe: ele é um expressado que existe apenas em sua expressão - a face de um equivalente da face. (1994, p. 17)

A cena é montada, o drama ou o dinamismo do conceito é estabelecido, por meio de uma imagem do espaço, como se uma câmera tivesse sido colocada no meio de uma paisagem incompreensível: nós não encontramos estruturas, nenhum ponto de referência, apenas um retângulo de espaço solto-digamos, de espaço exterior-dentro do qual, sem avisar, "um rosto amedrontado surge e olha para alguma coisa fora do campo.” Poderíamos dizer que as expressões amedrontadas referem-se a uma imagem fora da tela, porém à medida que esta imagem é capturada, a expressão também produz uma imagem não vista. Na ausência do que ele percebe, a face constitui uma estranha superfície refletora-mas refletir o quê? Por que esta expressão, este temor? Em seu trabalho, tanto juntos quanto individualmente, Deleuze e Guattari muitas vezes sugerem que o pensar, muito mais do que ser constante e inevitável, permanece contingente em circunstâncias ocasionais. Em outras palavras, se formos nos afastar do automatismo e dos hábitos, dos clichês, das opiniões, o pensamento exigirá uma provocação, até mesmo um tipo de violência.

É neste ponto que o construtivismo dos conceitos adquire sua complexidade paradoxal, pois enquanto “algo no mundo nos forçar a pensar”, o conceito em si não representará o mundo. O conceito, explicam Deleuze e Guattari, “não possuem coordenadas espaço-temporais, apenas ordenações intensas” (1994, p. 21). Na verdade, o conceito consiste nas sensações, intensidades, diferenças, que são selecionadas e incorporadas ao acontecimento 
de pensar. A este respeito, podemos invocar uma distinção Kantiana mais solta a fim de caracterizar o apocalipse de pensar e profetizar o sentido de sci phi que nos interessa aqui. Por quê? Ao despojar o conceito de qualquer sentido de representação, mesmo a representação do próprio apocalipse, Deleuze e Guattari desenvolvem seu construtivismo de acordo com o conceito de sublime de Kant, no processo de transformar seus constituintes em uma filosofia inteiramente diferente, não-representacional e in-substancial. Em Critique of Judgment , Kant divaga sobre a elaboração da razão em um império de julgamentos estéticos, cujo resultado produz aquelas eventualidades conceituais, ao mesmo tempo extraordinário (singular) e universal (ontogenético), que chamamos de o belo e o sublime. No último, Kant descreve uma experiência pela qual a sensação que encontramos-uma sensação que normalmente seria representada pela faculdade da imaginação e sob os auspícios do senso comum—provoca o colapso da imaginação. "Pois o sublime, no sentido exato da palavra, não pode estar contido em nenhuma forma sensorial,” explica Kant; ao contrário, o sublime "diz respeito a idéias da razão, as quais, embora não seja possível qualquer apresentação adequada das mesmas, podem ser ativadas e chamadas para dentro da mente pela própria inadequação que admite a apresentação sensorial” (KANT, 1978. p. 92). Mas o que é que não podemos imaginar ou representar a nós mesmos? O que é, em princípio, responsável por exercer isto?

Aqui, estamos interessados no sublime dinâmico, cuja provocação Kant elucida através de vários exemplos que variam de oceanos tumultuosos a caóticos campos de batalha. Porém, em todos os casos, escreve: "Se formos estimar a natureza como dinamicamente sublime, isso deve ser representado como uma fonte de temor...” (1978, p.109) Em outras palavras, Kant desloca a “causa” da sensação em favor da sensação em si, do temor, que é prolongada no colapso da imaginação. Resta à razão a tarefa de recolher os fragmentos espalhados, de sintetizar o colapso da imaginação, formando um conceito. Inspirado pelo mundo, a dinâmica do sublime, contudo, ocorre na ausência do mundo: a afeição faz surgir a ação da razão sobre a imaginação, a auto-afeição das faculdades atuando umas sobre as outras. "Desta forma, o amplo oceano agitado pelas tempestades não pode ser chamado de sublime” , escreve Kant. "Seu aspecto é horrível, e já deve ter armazenado em sua própria mente um rico estoque de idéias, se sua intuição for a de elevá-la à altura de um sentimento que seja sublime-sublime porque a mente foi incitada a abandonar a sensibilidade e a empregar-se de idéias que envolvam uma finalidade mais elevada” (1978, p. 92). O “sentimento" (Stimmung) predominante associado ao sublime é o poder, pois, ao contrário da experiência do belo, onde sentimos a harmonia de nossas faculdades com a natureza, no 
sublime, nós experienciamos o poder de nossas faculdades existirem na ausência da natureza, da substância, do mundo.

Se o sublime forma a base da dinâmica para um novo meio de conceitualização, ou sci phi, isto acontece porque, enquanto sua provocação apocalíptica é externa, seu procedimento existe sem a referência nem a representação do mundo. O sublime consiste, antes, no fracasso da representação, quando somos incapazes de imaginar-ou de fornecer uma imagem para—a experiência sensível. Para Kant, como sabemos, é a faculdade da razão que intervém para formar um conceito a partir do fracasso da imaginação, empreendendo, desta forma, um "trabalho do negativo” que jogará as circunstâncias tristes de uma faculdade contra a legislação imperiosa de outra. No entanto, como mostramos, o sublime consiste na coordenação de componentes ( a outra pessoa, a expressão de temor) que indica uma maneira inteiramente diferente de pensar. O sublime de Deleuze dramatiza a própria natureza de sua produção de conceitos, os quais são evocados por algo a que eles nunca se referem, mas que inscrevem na criação de conceitos. Nós não presenciamos o apocalipse, mas nos deparamos com outro cuja face, cujas emoções testemunham algo de fora, o desconhecido, o futuro.

\section{REFERÊNCIAS}

DELEUZE, G. Desert islands and other texts 1953-1974. Translation: M. Taormina. New York: Semiotext(e), 2004.

.; PARNET, C. Dialogues. Translation: H. Tomlinson and B. Habberjam. New York: Columbia University Press, 1987.

Difference and repetition, Translation: P. Patton. New York: University of Columbia Press, 1994.

Foucault. Translation: S. Hand. London and New York: Continuum Press, 1999.

Kant's critical philosophy: the doctrine of the Faculties. Translation: H. Tomlinson and B. Habberjam. Minneapolis: University of Minnesota Press, 1990.

.The logic of sense. Translation: M. Lester with C. Stivale, edited by C.V. Boundas. New York: Columbia University Press, 1990.

; GUATTARI, F. What is fhilosophy? Translation: H. Tomlinson and G. Burchell. New York: Columbia University Press, 1994.

KANT, I. The critique of judgment. Translation: J. Meredith. New York: Oxford, 1978. 
NIETZSCHE, F. The Gay Science, Translation: Walter Kaufmann. New York: Vintage Press, 1974.

On Truth and Lying in an Extra-moral sense. In: Nietzsche on rhetoric and

language. Ed. S. Gillman and C. Blair. New York: Oxford University Press, 1989.

Ph.D. em Literatura Comparada pela Universidade da Pensilvânia, e atualmente é professor Assistente no Departamento de Inglês e Literatura Comparada e professor Adjunto no Departamento de Estudos da Comunicação, ambos cargos na Universidade da Carolina do Norte, Chapel

http://english.unc.edu/faculty/flaxmang.html

E-mail: gflax@email.unc.edu 